\title{
Research Advance on Accelerating Anaerobic Sludge Granulation Process
}

\author{
Xin-Long JIANG ${ }^{1, \text { a }}$, Yi-Hua JIANG ${ }^{1, b}$, Jiang-Qun WANG ${ }^{2, c}, Y u-Y u n Z^{2}$ HEN $^{2, d}$ \\ ${ }^{1}$ Zhejiang Shuren University, Hangzhou, China, \\ ${ }^{2}$ Huarun Snow Beer (Zhejiang) Co., Ltd., Hangzhou, China

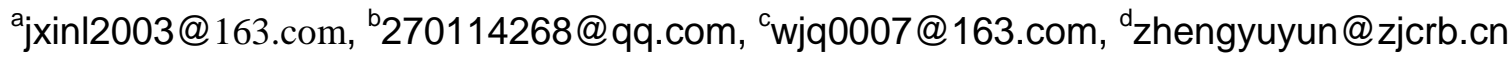

Keywords: Sludge Granulation Process, Mechanisms, Influencing Factors, Additive, Wastewater Treatment Technology.

\begin{abstract}
The application of sludge granulation was regarded as one of the promising biotechnologies in wastewater treatment. Anaerobic sludge granulation process is a multistage process that is decided by many factors such as operational condition, substrate and so on. After summarizing the existing mechanisms of anaerobic sludge granulation, the paper overviews the research situation and development of accelerating anaerobic sludge granulation process from three aspects of the activity ensureing of anaerobic, screening of accelerating agents and hydrodynamic shear forces in the past few years. There will be a wider application foreground for it. At last, some comments and suggestions have been put forward. Hope to supply the specified theory base for the project technique of anaerobic sludge granulation.
\end{abstract}

\section{Introduction}

Because the upflow anaerobic sludge blanket (UASB) reactor have high biomass concentration and rich microbial diversity, it is considered desirable in high-strength organic wastewater treatment [1-2]. Anaerobic granular sludge is the core component of an UASB reactor. Sludge granules are dense, multi-species, microbial communities, and none of the individual species in the granular ecosystem is capable of degrading complex organic wastes. One major drawback of the UASB reactor is its extremely long start-up period, which generally requires 2-8 months for the development of anaerobic granular sludge. A general four-step model for anaerobic granulation is to propose as follows:physical movement to initiate bacterium-to-bacterium contact or bacterial attachment onto nuclei $\rightarrow$ initial attractive forces to keep stable multicellular contacts $\rightarrow$ microbial forces to make cell aggregation mature $\rightarrow$ steady state three-dimensional structure of microbial aggregate shaped by hydrodynamic shear forces [3]. In order to reduce the space-time requirements of bioreactors and eventually lead to a cheaper treatment of high strength wastes, strategies for expediting granular formation are highly desirable. For achieving such a purpose, the ensureing of anaerobic activity,screening of accelerating agents and hydrodynamic shear forces should be thoroughly understood. This paper attempts to review the above three aspects for anaerobic granulation in UASB, and the application prospect of accelerating anaerobic sludge granulation.

\section{Anaerobic Activity to Ensure}

\section{Nutrient}

The existing of nutrients such as nitrogen, phosphorus and sulfur in the influent is fundamentally needed to accomplish a successful development of granules. Surplus nutrients into influent can enhance the process and have no deadly effect throughout the first phases of granules formation basically. While lack of nutrients in substrate can adversely affect the granules formation process, whereby it has been reported that at a nitrogen concentration of less than $300 \mathrm{mg} / \mathrm{L}$ has resulted in granules growth dwindling [4]. In addition, over-elevated concentration of nutrients has resulted in process inhibition [5]. Nutrients advantages can be significantly demonstrated in preventing granules flotation as well as reducing the effect of shocks[6]. 


\section{Temperature}

The methanogens are relatively more affected by temperature than acidogens.Many kinds of microorganisms are more acclimatized in mesophilic temperature range. It is reported that the optimum range for microorganisms growth is between $(30 \sim 40)^{\circ} \mathrm{C}$ in mesophilic reactors, and in relation to the thermophilic temperature, they classified the ranges according to the microorganisms species suitability, whereby for Methanosarcina sp. the optimum temperature for growth is $(55 \sim 58)^{\circ} \mathrm{C}$, methanobacterium species $(65 \sim 70)^{\circ} \mathrm{C}$, and acetateutilizing mixed culture $(60 \sim 65)^{\circ} \mathrm{C}$ [7]. However, rising the temperature of reactor may result in disintegration of some species of microorganisms and prosperity of the other in versus. Mesophilic granules has more sensitivity against temperature shocks than thermophilic granules [8].It is reported that mesophilic condition for seed sludge is more active and taking less time for start-up operation period than thermophilic condition [9]. While much gab in temperature effect of granulation process and development are existing and also strong scientific justifications for the deference of granules structure in each mesophilic and thermophilic are still unclear.

\section{PH and Alkalinity}

In general, neutral $\mathrm{pH}$ as well as elevated partial pressure of hydrogen is significantly essential for high quality granules formation.According to the nature of microorganisms, methanogenic microorganisms seems to be more sensitive in case of $\mathrm{pH}$ fluctuation than acidogenic microorganisms, whereby typical range of $\mathrm{pH}$ more than 6.3 is suitable for the latest kind. Practically, implementation of $\mathrm{pH}$ less than 6.3 will result in prevailing acidic formation which is mainly prevented the methanogens formation as well as methane production [10]. Due to the increase or variation in organic loading rate,alkalinity plays a significant role on fluctuations neutralization in volatile fatty acids concentration which is always ready to arise [11]. It is reported that the typical values of alkalinity have to be in the range of 250 to $950 \mathrm{mg} / \mathrm{L}$ [12].

\section{Organic Loading Rate}

Organic loading rate (OLR) can be considered as the most critical factor that should be carefully adjusted, it is easily to control that factor via COD influent adjustment or adjusting the inflow rate [13]. The disadvantages of OLR decrease are mainly represented by its negative role of disintegrating big granules as a result of lacking in food, where an organic loading rate of $(\leq 1.5) \mathrm{kg} \mathrm{COD} / \mathrm{m}^{3} . \mathrm{d}$ is not recommended and resulted in granules degeneration [14].On the other hand, increase the organic loading rate up to reasonable limit is totally resulted in volatile fatty acids accumulation where the latest will decrease the $\mathrm{pH}$ of reactor [15]. Organic loading rates of (2-4.5) $\mathrm{kg} \mathrm{COD} / \mathrm{m}^{3}$.d has been recommended for high-quality growth of granules [16]. It can believe that during start-up operation and granules formation, the implementation OLR values must be carefully located to obtain good growth.

\section{Enhancement of Granulation by Growth Nuclei}

\section{The Addition of Inert Material}

The addition of inert material such as clay, aggregate, granular activated carbon during the start-up of UASB reactors,surface properties with particulate matter, speed up the bacteria on the surface of the accumulation, form core carrier of granular sludge and shorten the time of occurrence of granular sludge. Ross [17] reported that the presence of spent powdered active carbon enhanced the settleability of a sludge treating maize-processing effluent.The carbon provides an additional surface area for attached-growth bacteria, which increases the density of the resultant biomass, with concomitant improved settling.But if adding excess particles will mutually impact, friction in hydraulic scouring and biogas stirring, resulting in strongly cut, hinder the early adult aggregation and adhesion, the granular sludge growth is harmful. the main advantage of add the materials are from the broad and slightly lower cost. The addition inert material are not biodegradable, reduces the 
effective volume of UASB reactors.In addition,it can influence effect of sludge bulking and mass transfer with the proportion of the sludge increased.

\section{The Addition of Synthetic and Natural Polymers}

Synthetic polymers have been widely used in water coagulation and flocculation processes, and can significantly promote particle agglomeration. The synthetic polymers can also be applied to expedite the development of UASB granules similarly. It was found that the supplementation of polymer Chitosan, which has a similar structure to polysaccharides, significantly enhanced the formation of anaerobic granules in USAB reactors, the granulation rate in the Chitosan-containing reactor was 2.5-fold higher than that in the control reactor without addition of the polymer, while the specific activities of methane production were comparable in both reactors [18]. Freely moving polymeric chains may form a bridge between cells, and this would facilitate the formation of initial microbial nuclei, which is the first step towards granulation.Adding different organic polymers are to accelerate the sludge granulation effect is obvious.

The most organic matter added can be degraded end, granular sludge is beneficial to enhance the formation of the activity. The sludge is negatively charged, investment should be the organic polymer with cationic type, but the type of material has certain toxicity for microorganism or will inhibit anaerobic microbial activity basically.If add too little, effect will be not obvious. The dosage of master is very important and the optimal dosage must be determined by test in using this method at first. In addition, the addition of high cost of material also affects its practical application.

\section{The Addition of Cations and Heavy Metals}

Since bacteria have negatively charged surfaces under usual $\mathrm{pH}$ conditions, a basic idea to expedite anaerobic granulation process is to reduce electrostatic repulsion between negatively charged bacteria by introducing multi-valence positive ion, such as calcium, aluminum, ferric or magnesium ions, into seed sludge. Reduced electrostatic repulsion between bacteria would promote anaerobic granulation [19]. Addition of $\mathrm{Ca}^{2+}$ with concentrations of $80-200 \mathrm{mg} / \mathrm{l}, \mathrm{Mg}^{2+}$ of $12-120 \mathrm{mg} / \mathrm{l}, \mathrm{Al}^{3+}$ of $300 \mathrm{ml} / \mathrm{l}$ or $\mathrm{Fe}^{2+}$ of $300 \mathrm{ml} / \mathrm{l}$ was found to increase the rate of anaerobic granulation in UASB reactors [20-22]. In addition, the multi-valence positive ion may promote sludge granulation by bonding with extracellular polymers (ECPs). The high affinity between ECPs and calcium ion had been shown [24]. This in turn implies that calcium ion may bridge ECPs and ECPs and link cells and ECPs together to form an initial three dimension structure of microbial community, in which bacteria can further grow.However, the overload of minerals existing in UASB reactor have absolutely led to process inhibition, and also caused ash formation instead of activated granules.

\section{Hydrodynamic Shear Forces}

The hydraulic conditions of hydraulic shear stress is one of key factors that affect the formation of granular sludge and characteristics of granular sludge[25]. High hydraulic conditions, can increase the chance of bacterial or between bacteria and inert particles meet so as to enhance the nucleation rate,can enhance the mass transfer.But the hydraulic condition is too strong, will cause shear granular sludge and peeling extracellular polysaccharide sticky layer of somatic cell not clustered,impede the adhesion and aggregation. The hydraulic condition is too weak, would lead to a large number of dispersed sludge excessive growth, thus affecting the sludge settling properties, and even cause sludge bulking [26]. Therefore, in the initial, should use the low hydraulic load of $(0.05-0.1) \mathrm{m}^{3} / \mathrm{m}^{2}$ $\cdot h$,the floc sludge can stick to each other, is conducive to the primary body the formation of granular sludge. When there is a certain amount of sludge, increasing the hydraulic load exceeds to $0.25 \mathrm{~m}^{3} / \mathrm{m}^{2}$ $\cdot h$, can be washed away part of the granular sludge floc sludge, sink to the bottom of the reactor with the larger density, form the granular sludge layer. In order to achieve the granular sludge as soon as possible, the hydraulic load is increased to $0.6 \mathrm{~m}^{3} / \mathrm{m}^{2} \bullet \mathrm{h}$, can be washed away most of the floc sludge. However, increasing the hydraulic load can not be too fast, otherwise, a large number of floc sludge out prematurely will lead to excessive sludge load and influence stable running of the reactor[26]. 


\section{Outlook}

For the UASB reactor, the key lies of organic wastewater treatment is in whether the efficient train with the anaerobic granular sludge of high performance and good sedimentation. According to the influence factors of sludge granulation, we can consider in addition polymers, inert particles, inorganic salt, and the optimization of process parameters at the same time, the realization of multi factor control, accelerate the sludge granulation process. To promote engineering application technology of granular sludge, should strengthen the following aspects of the research:

(1) The granular sludge is a very promising technology in the treatment of high toxicity and high load of organic wastewater. In fact, anaerobic biological method is also suitable for the treatment of the city life sewage and other low concentration wastewater. Promoting the formation of granular sludge on the treatment of low concentration wastewater is one of the important aspects of future research.

(2) Some microbial flocculant not only can accelerate the particles, but also can improve the methanogenic activity of granular sludge.The future research can focus on finding the granular sludge accelerator with microbial flocculant of the promoting effect better, easy biodegradation, and does not produce two pollution.

(3) In order to degrade wastewater of difficult to be biodegraded in high efficiency and rapid degradation, adding dominant bacteria of through domestication and screening, the preparation of granular sludge,treatment industrial wastewater of specific refractory, toxic.

(4) we can be use combined with sludge granulation technology and other wastewater treatment technology, and realize the complementary advantages of two or more technology.

\section{Acknowledgments}

This work was supported by bureau of Hangzhou city science and technology project(No.20130533B64).

\section{References}

[1] Schmidt JE, Ahring BK. Granular sludge formation in upflowanaerobic sludge blanket (UASB) reactors. Biotechnol Bioeng, 1996, 49: 229-46.

[2] Wu JH, Liu WT, Tseng IC, Cheng SS. Characterization of microbial consortia in a terephthalate-degrading anaerobic granular sludge system. Microbiol, 2001, 147: 373-82.

[3] Liu Y, Xu H L, Yang S F, Tay J H.Mechanisms and models for anaerobic granulation in upflow anaerobic sludge blanket reactor.Water Research, 37 (2003) $661-673$.

[4] Singh, R, P, Kumar, S, and Ojha, C. S. P. Nutrient requirement for UASB process: a review. Biochem Eng J, 1999, 3, 35-54.

[5] Jarrell, K, F and Kalmokoff, M, L. Nutritional requirements of the methanogenic archaebacteria. Can J Microbiol, 1988, 34, 557-576.

[6] Alphenaar, P, A, Sleyster, R, and De Reuver, P. Phosphorus requirement in high-rate anaerobic wastewater treatment. Water Res, 1993, 27, 749-756.

[7] Zinder, S, H. Conversion of acetic acid to methane by thermophiles. FEMS Microbiol Rev, 1990, $75,125-138$.

[8] Van Lier, J, B, J, Rintala, Sanz Martin, J, L, and G, Lettinga. Effect of short-term temperature increase on the performance of a mesophilic UASB reactor. Water Sci Technol, 1990, 22, 183- 190.

[9] Syutsubo, K, Harada, H, Ohashi, A, and Suzuki, H. An effective start-up of thermophilic UASB reactor by seeding mesophilically- grown granular sludge. Water Sci Technol, 1997, 24, 35-59. 
[10] Van Haandel, A,C and Lettinga, G. Anaerobic sewage treatment: a practical guide for regions with a hot climate. Wiley, Chichester, England, 1994.

[11] Isik, M and Sponza, D, T. Effects of alkalinity and co-substrate on the performance of an upflow anaerobic sludge blanket (UASB) reactor through decolorization of Congo red azo dye. Bioresour Technol, 2005, 96, 633-643.

[12] Singh, R, P, Kumar, S, and Ojha, C. S. P. Nutrient requirement for UASB process: a review. Biochem Eng J, 1999, 3, 35-54.

[13] Manoj, K, T, Saumyen, G, Harendranath, S, and Shweta, T. Influence of extrinsic factors on granulation in UASB reactor. Appl Microbiol Biotechno, 2006, 71, 145-154.

[14] Dohanyos, M, Kosova, B, Zabranska, J, and Grau, P. Production and utilization of volatile fatty acids in various types of anaerobic reactors. Water Sci Technol, 1985, 17, 191-205.

[15] Ahn, Y, H, Song, Y, J, Lee, Y, J, and Park, S. Physicochemical characterization of UASB sludge with different size distributions. Environ Technol, 2002, 23, 889-897.

[16] Ghangrekar, M, M, Asolekar, S, R, and Joshi, S, G. Characteristics of sludge developed under different loading conditions during UASB reactor start-up and granulation. Water Res, 2005, 39, 1123-1133.

[17] Ross WR.Anaerobic digestion of industrial effluents with emphasis on solids-liquid separation and biomass retention.Ph.D.Thesis, University of the Orange Free State, South Africa, 1984.

[18] El-Mamouni R, Leduc R, Guiot SR. Influence of synthetic and natural polymers on the anaerobic granulation process. Water Sci Technol 1998; 38: 341-347.

[19] Yu HQ, Tay JH. Fang HHP The role of calcium in sludge granulation during UASB reactor start-up. Water Res 2001; 35: 1052-1060.

[20] Teo KC, Xu HL, Tay JH. Molecular mechanism of granulation-II: proton translocating activity. J Environ Eng 2000; 126: 411-418.

[21] Schmidt JE, Ahring BK. Effects of magnesium on thermophilic acetate-degrading granules in upflowanaerobic sludge blanket (UASB) reactor. Enzyme Microbial Technol 1993; 15: 304-310.

[22] Yu, HQ Fang, HHP and Tay JH.Effect of $\mathrm{Fe}^{2+}$ on Sludge Granulation in Upflow Anaerobic Sludge Blanket Reactor. Water Sci. Techno 2000, 199-215.

[23] Yu HQ, Fang HHP, Tay JH. Enhanced sludge granulation in upflowanaerobic sludge blanket (UASB) reactors by aluminum chloride. Chemosphere 2001;44:31-36.

[24] Rudd T, Sterritt RM, Lester JN. Complexation of heavy metals by extracellular polymers in the activated sludge process. J W ater Pollut Control Fed 1984; 56: 1260-1268.

[25] O'Flaherty V, Lens PNL, de Beer D, Colleran E (1997) Effect of feed composition on aggregate characteristics in anaerobic upflow reactors. Appl Microbiol Biotechnol 47: 102-107.

[26] G.Lettinga. Proc. Of the sem iner/workship on Anaerobic Treatment of sewage, 1985, 369-380. 